\title{
Concentrated growth factor promotes Schwann cell migration partly through the integrin $\beta 1$-mediated activation of the focal adhesion kinase pathway
}

\author{
JIE QIN ${ }^{1,3}$, LIN WANG $^{2}$, LING ZHENG $^{4}$, XIAOYAN ZHOU ${ }^{5,6}$, \\ YIDI ZHANG ${ }^{1}$, TINGTING YANG ${ }^{1}$ and YANMIN ZHOU ${ }^{1,3}$
}

\begin{abstract}
${ }^{1}$ Departments of Dental Implantology and ${ }^{2}$ Very Important People, School and Hospital of Stomatology, Jilin University; ${ }^{3}$ Jilin Provincial Key Laboratory of Tooth Development and Bone Remodeling, Changchun, Jilin 130021; ${ }^{4}$ Department of Stomatology, Xuan Wu Hospital, Capital Medical University, Beijing 100053, P.R. China; ${ }^{5}$ Institute of Dental Research, Westmead Centre for Oral Health and Westmead Millennium Institute, Sydney, NSW 2145;

${ }^{6}$ Department of Oral Biology, Faculty of Dentistry, University of Sydney, Sydney, NSW 2010, Australia
\end{abstract}

Received September 21, 2015; Accepted March 1, 2016

DOI: $10.3892 / \mathrm{ijmm} .2016 .2520$

\begin{abstract}
Nerve injury is a serious complication associated with dental implant surgery. Following nerve injury, the migration of Schwann cells (SCs) supports nerve regeneration. Concentrated growth factor (CGF) belongs to a new generation of biomaterials that contain fibrin matrix, as well as a number of growth factors that affect the migration of various types of cells, including endothelial cells and cancer cells. To the very best of our knowledge, there are no available studies to date on the promoting effect of CGF on the migration of SCs. Thus, the aim of the present study was to characterize the structure of CGF and growth factor release, examine the effects of CGF on the migration of SCs, and to examine the role of integrin $\beta 1$ and the focal adhesion kinase (FAK) pathway in the CGF-induced migration of SCs. For this purpose, CGF was prepared by centrifuging rat venous blood, which produced a fiber-like matrix capable of releasing transforming growth factor- $\beta 1$ (TGF- $\beta 1$ ) over a sustained period of time (at least 13 days). The soluble component of CGF was used to produce conditioned media to treat the SC cells in culture. The results demonstrated that CGF promoted the migration of SCs and increased the expression of integrin $\beta 1$. These effects appeared to involve FAK phosphorylation, which occurred downstream of integrin $\beta 1$ activation. The short-interfering RNA (siRNA)mediated downregulation of integrin $\beta 1$ expression did not block the ability of CGF to promote the migration of SCs. These data suggest that CGF promotes the migration of SCs partly through the integrin $\beta 1$-mediated activation of the FAK pathway.
\end{abstract}

Correspondence to: Professor Yanmin Zhou, Department of Dental Implantology, School and Hospital of Stomatology, Jilin University, 1500 Qinghua Road, Changchun, Jilin 130021, P.R. China E-mail: zhouym62@126.com

Key words: nerve regeneration, concentrated growth factor, Schwann cell, migration, integrin $\beta 1$, focal adhesion kinase

\section{Introduction}

Dental implants have been widely used to replace missing teeth. Despite promising results, implant treatment is associated with a considerable rate of complications, particularly following the surgical procedures. Nerve injury is one of the most serious complications of implant surgery (1), which usually involves the sensory nerves of the mandible, including the lingual, inferior alveolar and mental nerves. Present treatments for peripheral nerve injury include pharmacological therapy, physical rehabilitation and invasive treatments, such as microsurgery; however, these options require a long-term period for nerve recovery and usually do not result in satisfactory functional recovery (2). Therefore, there is a great need for alternative approaches which promote the regeneration of the damaged neural tissues more effectively and rapidly.

A critical prerequisite for the regeneration of peripheral nerves following injury is the migration of Schwann cells (SCs), which are the major glial cell of the peripheral nerve system $(3,4)$. A number of cytokines, such as nerve growth factor and erythropoietin, have been reported to promote the migration of SCs $(5,6)$. However, frequent injections are required to maintain cytokine levels in order to sustain the regenerative effects and, therefore, this type of treatment is inconvenient and costly for the patient (7-9). To overcome these limitations, new regenerative strategies are required which are more effective and convenient for the patient.

Platelet concentrates are increasingly used in regenerative medicine due to their sustained release of cytokines from degraded platelets and leukocytes (10-12). These cytokines mainly include transforming growth factor- $\beta 1$ (TGF- $\beta 1$ ), vascular endothelial growth factor (VEGF), insulin growth factor (IGF), platelet-derived growth factor-AB (PDGF-AB), and interleukin-1 $\beta$ (IL-1 $\beta$ ) (10-12). Several generations of platelet concentrates have been developed. Platelet-rich plasma (PRP), the first generation of platelet concentrates, has been reported to promote the migration of SCs. However, PRP is prepared by centrifuging venous blood with the addition of 
bovine thrombin, an animal-derived biological product, which may lead to the transmission of unknown infections (13).

Concentrated growth factor (CGF) belongs to the latest generation of platelet concentrates (Sacco, 2006; unpublished data), which is produced by the centrifugation of venous blood without the addition of any exogenous products and is therefore free from cross-contamination. Additionally, CGF has a complex three-dimensional architecture, composed of a platelet, leukocyte and growth factor-rich fibrin biomaterial (14). It has been principally applied for the regeneration of alveolar and sinus bone (15). Recently, it has also been found to increase the proliferation of periodontal ligament cells (16). However, the possible promoting effect of CGF on the migration of SCs, as well as the associated molecular mechanisms have not yet been fully investigated. One suggested mechanism for the promoting effect of CGF on the migration of SCs is through the activation of integrins.

Integrins, which are cell surface glycoproteins, are in fact heterodimers of $\alpha$ and $\beta$ subunits that modulate cell migration (17). SCs exhibit an increased expression of integrin $\beta 1$ following nerve injury (18). It has been demonstrated that integrin $\beta 1$ plays a necessary role in the migration of SCs promoted by erythropoietin and VEGF $(6,19)$. However, to the best of our knowledge, there are no studies available to date on the role of integrin $\beta 1$ in the CGF-induced migration of SCs.

Therefore, in this study, we investigated the following: i) the structure of CGF and its effects on the migration of SCs and ii) the possible role of integrin $\beta 1$ in the CGF-induced migration of SCs. The following hypotheses were examined: i) CGF possesses properties which allow the sustained release of growth factors; ii) CGF increases the migration of SCs; iii) integrin $\beta 1$ and subcellular downstream signaling [namely focal adhesion kinase (FAK)] are activated following treatment with CGF; and iv) the short-interfering RNA (siRNA)-mediated downregulation of integrin $\beta 1$ decreases the CGF-induced migration of SCs.

\section{Materials and methods}

Preparation of CGF extract. In the present study, all the experiments were performed in accordance with the Guidance Suggestions for the Care and Use of Laboratory Animals, formulated by the Ministry of Science and Technology of China. CGF was prepared according to the following protocol as previously described (14): briefly, $5 \mathrm{ml}$ venous blood was drawn from the inferior vena cava of Wistar rats (weighing $250 \mathrm{~g}$ ). Blood was collected into a sterile tube without any anticoagulants and immediately centrifuged in a Medifuge centrifuge (Silfradent S.R.L., Sofia, Italy). Following centrifugation, the blood had separated into 3 layers due to the different densities of the blood components. CGF was the middle layer; it was mechanically separated using scissors and gently compressed into a thin membrane. Each membrane was soaked in $5 \mathrm{ml}$ fresh Dulbecco's modified Eagle's medium (DMEM; Gibco, New York, NY, USA) without fetal bovine serum (FBS) in a $15 \mathrm{ml}$ centrifuge tube (Corning Glassworks, Corning, NY, USA). The medium, named CGF extract, was collected 7 days later and centrifuged at $400 \mathrm{xg}$ for $5 \mathrm{~min}$ to pellet the platelets and red blood cells. All the extractions were stored at $-80^{\circ} \mathrm{C}$ for future use.
Scanning electron microscopy. The CGF membrane was fixed in $2.5 \%$ glutaraldehyde solution and $1 \%$ osmium tetroxide (both from Sigma-Aldrich, St. Louis, MO, USA). It was dehydrated serially in 50, 70, 80, 90 and 100\% ethanol. After drying, the sample was coated with gold, and images were captured under a scanning electron microscope (SEM; S-3400N; Hitachi High Technologies America, Schaumburg, IL, USA). Fibrin fiber diameter and percentage porosity were measured on the SEM images using ImageJ software (version 1.49; Wayne Rasband, National Institutes of Health, Bethesda, MD, USA). Briefly, the diameters of 6 randomly selected fibers were measured using the tool. Percentage porosity was determined by the particle analysis function in the image analysis software.

Enzyme-linked immunosorbent assay (ELISA). We hypothesized that the growth factors, which are trapped within the fibrin meshes of CGF, are released in a controlled manner over a long-term period. Thus, we examined the state of the growth factors released from the CGF extract over time. Briefly, the CGF membrane was soaked in $5 \mathrm{ml}$ DMEM without FBS in a $15 \mathrm{ml}$ flacon tube and incubated at $37^{\circ} \mathrm{C}$. The medium was collected on days $1,3,5,7,9,11$ and 13 and following collection, $5 \mathrm{ml}$ fresh DMEM was added to each tube. All the collected extracts were stored at $-80^{\circ} \mathrm{C}$. TGF- $\beta 1$ levels were determined using a commercially available ELISA kit (Elabscience, Wuhan, China) according to the manufacturer's instructions. All the assays were performed in triplicate.

Analysis of cell migration using the scratch wound-healing assay. The RSC96 SCs (obtained from Chinese Academy of Sciences, Shanghai, China) were seeded into 6-well plates at a density of $5 \times 10^{5}$ cells/well. After reaching confluence, a scratch was made on the cell monolayer using a P10 pipette tip according to the protocol previously described by Liang et al (20). Cellular debris was then washed off using phosphate-buffered saline (PBS). DMEM or CGF were then added to the culture plates. Images of the cells were captured using an Olympus DP-50 digital microscope camera (Olympus Optical Co., Ltd., Tokyo, Japan) immediately after wounding and again $24 \mathrm{~h}$ later. Reference points were made on the outer bottom of the plates to mark the location of the scratch in order to obtain the same field. The distance between the edges of the scratch was measured using cellSens Entry software (Olympus Life Science, Hamburg, Germany). The migration rate was calculated using the following equation: migration rate $=\left(\mathrm{D}_{0}-\mathrm{D}_{24}\right) / \mathrm{D}_{0} \times 100$, as previously described (21). $\mathrm{D}_{0}$ is the distance at the time of making the scratch wound, and $\mathrm{D}_{24}$ is the corresponding distance $24 \mathrm{~h}$ later.

Western blot analysis. The protein expression of integrin $\beta 1$ and phosphorylated (p-)FAK was examined by western blot analysis. The RSC96 SCs were treated with DMEM or CGF extract supplemented with 10\% FBS (Gibco, Melbourne, Australia). At 1, 2 and 3 days, the cells were washed twice using PBS, and then lysed in ice-cold lysis buffer [radioimmunoprecipitation assay buffer with $1 \%$ phenylmethylsulfonyl fluoride (Biyuntian, Beijing, China)] on ice for $1 \mathrm{~h}$. The cell lysates were collected and centrifuged at approximately $400 \mathrm{x}$ g. The protein concentrations were determined using the bicinchoninic acid (BCA) assay. Equal amounts of protein $(40 \mu \mathrm{g})$ were loaded onto a $10 \%$ SDS-polyacrymide gel and electrophoretically transferred 
onto polyvinylidene fluoride membranes (Millipore, Bedford, MA, USA). After blocking in Tris-buffered saline with $0.05 \%$ Tween-20 (TBST) containing 5\% skimmed powdered milk for $90 \mathrm{~min}$, the membranes were washed thrice with TBST and then incubated with primary antibodies against either integrin $\beta 1$ (polyclonal antibody, rabbit anti-rat, 1:500, Cat. no. bs-0486R; Bioss, Wuhan, China) or p-FAK (polyclonal antibody, rabbit anti-rat, 1:1,000, cat no. AP0437; ABclonal, Cambridge, MA, USA) overnight at $4^{\circ} \mathrm{C}$. The samples were eluted 4 times with TBST and then incubated with horseradish peroxidase (HRP)-conjugated secondary antibodies (goat anti-rabbit, 1:1,000, cat. no. AS014; ABclonal). An ECL chemiluminescence assay was used for the chemiluminescence-based immunodetection of HRP. The intensities of the bands (representative of protein levels) were determined using ImageJ software (version 1.49; Wayne Rasband, National Institutes of Health). $\beta$-actin was used to normalize target proteins.

Construction of plasmid vector expressing integrin $\beta 1$ siRNA. During RNA intereference (RNAi), siRNAs may serve as guides for the enzymatic cleavage of complementary RNAs, thereby inhibiting sequence-specific gene expression. RNAi is an effective tool for the analysis of gene function (22). In the this study, a plasmid vector synthesizing siRNA was constructed in order to suppress the gene expression of integrin $\beta 1$ in the SCs. Briefly, siRNA were synthesized by Sangon Biotech (Shanghai, China). The siRNAs with the targeting sequences GAAGGGTTGCCAACCAAGT, GACATGGATGCTTA CTGCA and GGTGGCTTTGATGCAATCA were labeled as siRNA-1, siRNA-2 and siRNA-3, respectively. All the siRNAs were annealed and ligated into the pRNA-H1.1 plasmid between the HindIII and the BamHI sites. The normal plasmid without siRNA was used as a control, labeled as siRNA-N. A volume of $20 \mu \mathrm{l}$ of the recombinant plasmids was transformed into $100 \mu \mathrm{l}$ E. coli strain JM109, and the cells were then plated onto Luria-Bertani (LB) plates containing $10 \mathrm{~g}$ of tryptone, $5 \mathrm{~g}$ of yeast extract, $5 \mathrm{~g}$ of $\mathrm{NaCl}, 100 \mathrm{mg}$ of ampicillin, and $15 \mathrm{~g}$ of agar per liter and incubated at $37^{\circ} \mathrm{C}$. The colony was picked up and the plasmids were extracted. All the plasmids were verified by DNA sequence analysis.

Integrin $\beta 1$ gene silencing. The RSC96 cells were cultured in dishes to obtain $70-90 \%$ confluence without antibiotics. The cells were then transfected with siRNA-1, siRNA-2, siRNA-3 or siRNA-N, using transfection reagent (Lipofectamine 2000; Invitrogen, Carlsbad, CA, USA) according to the manufacturer's instructions. The medium was replaced with DMEM supplemented with $10 \%$ FBS $4 \mathrm{~h}$ after transfection. The protein expression of integrin $\beta 1$ after gene silencing was determined using western blot analysis as described above.

Reverse transcription-quantitative polymerase chain reaction $(R T-q P C R)$. The mRNA expression of integrin $\beta 1$ following the application of siRNA was analyzed by RT-qPCR. Total RNA was extracted using TRIzol reagent (Invitrogen) and was then reverse transcribed using the RevertAid kit (Takara Bio, Otsu, Japan) according to the manufacturer's instructions. SYBR-Green qPCR Super Mixture (Takara Bio) was used to assess gene expression on an Exicycler 96 Realtime PCR system (Bioneer, Daejeon, Korea). The samples were normalized to $\beta$-actin. The following primer sequences were used: rat integrin $\beta 1$ forward, 5'-TTGCCAACC AAGTGACATA-3' and reverse, 3'-GGTAGTCTTCAG CCСТCTT-5'; and rat $\beta$-actin forward, 5'-GGAGATT ACTGCCCTGGCTCCTAGC-3' and reverse, 3'-GGCCGGA CTCATCGTACTCCTGCTT-5'. The following amplification conditions were used: $95^{\circ} \mathrm{C}$ for $10 \mathrm{~min}$ followed by 40 cycles of $95^{\circ} \mathrm{C}$ for $10 \mathrm{sec}, 60^{\circ} \mathrm{C}$ for $20 \mathrm{sec}$ and $72^{\circ} \mathrm{C}$ for $30 \mathrm{sec}$. All the samples were run in triplicate in each experiment. Changes in gene expression were calculated using the $2^{-\Delta \Delta \mathrm{Ct}}$ method.

Transwell migration assay. The migration of the RSC96 SCs following integrin $\beta 1$ gene silencing was examined using $6.5 \mathrm{~mm}$ Transwell chambers with $8 \mu \mathrm{m}$ pores (Corning Costar, Corning, NY, USA). CGF or DMEM supplemented with $20 \%$ FBS was added to the lower wells to act as a chemoattractant. The cells were trypsinized, washed in PBS and then added to the upper Transwell chambers $\left(1 \times 10^{4}\right.$ cells/well $)$ and allowed to migrate for $24 \mathrm{~h}$. The non-migrated cells were removed from the upper chambers using a cotton swab. The migrated cells were fixed with paraformaldehyde, stained with $0.5 \%$ crystal violet (Amresco, Solon, OH, USA), and then counted in 5 fields/ well under a microscope (x200 magnification).

Statistical analysis. Data are expressed as the means \pm standard deviation and were analyzed using one-way analysis of variance (ANOVA) with the Tukey HSD comparison test or using the independent-samples t-test. A P-value $<0.05$ was considered to indicate a statistically significant difference.

\section{Results}

Structural characterization of CGF. The biological properties of CGF were evaluated as a first step. CGF was generated by centrifuging whole blood. There were 3 layers following centrifugation (Fig. 1A): the upper layer is a clear fluid which is the blood serum; the middle layer is CGF which is composed of a large and dense polymerized fibrin block with aggregated platelets and growth factors; the bottom layer is composed of red blood cell debris. CGF was mechanically separated using scissors and then compressed into a thin membrane. Surface parameters such as topography and hardness markedly affect cell behavior and the release of growth factors $(10,12,23)$. SEM analysis (Fig. 1B) revealed that CGF had a fiber-like appearance. The diameter of the fibers was $0.36 \pm 0.14 \mu \mathrm{m}$ and the percentage porosity was $40.44 \pm 2.97 \%$. The fibrin fiber network in CGF was sparse, with many platelet aggregates or red blood cells trapped in the spaces between the fibrin fibers.

Release of growth factors. TGF- $\beta 1$ is one of the growth factors secreted by platelets $(24)$ and has neuroprotective effects $(25,26)$. Thus, the secretion of TGF- $\beta 1$ was measured by ELISA in the present study. In a sustained-release test, it was found that CGF slowly released TGF- $\beta 1$ for up to 13 days (Fig. 2). The level of TGF- $\beta 1$ increased from $75 \mathrm{pg} / \mathrm{ml}$ on day 1 to $130 \mathrm{pg} / \mathrm{ml}$ on day 7 . Subsequently, the level slowly decreased to $60 \mathrm{pg} / \mathrm{ml}$ on day 13 .

$C G F$ promotes cell migration. To examine the effects of CGF on the migration of RSC96 SCs, a scratch woundhealing assay was performed (Fig. 3). The scratch assay is a 
A

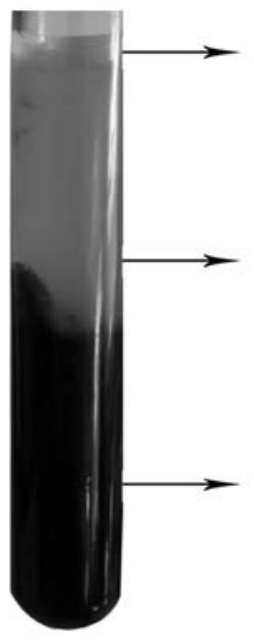

$\mathrm{B}$

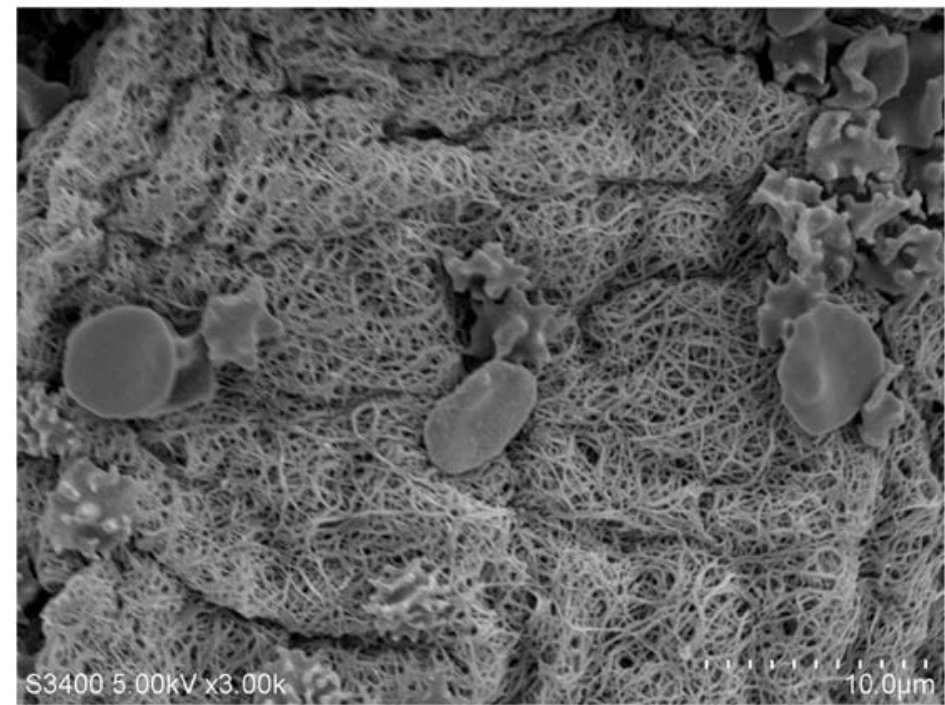

Figure 1. Structural characterization of concentrated growth factor (CGF). (A) The blood is separated into 3 layers following centrifugation: the transparent layer at the top is the serum; the layer in the middle is CGF which is composed of a large and dense polymerized fibrin block with aggregated platelets and growth factors; the layer at the bottom is composed of of red blood cell debris. (B) Scanning electron microscope (SEM) images of CGF. CGF exhibited a fiber-like appearance. The diameter of the fibers was $0.36 \pm 0.14 \mu \mathrm{m}$ and the percentage porosity was $40.44 \pm 2.97 \%$.

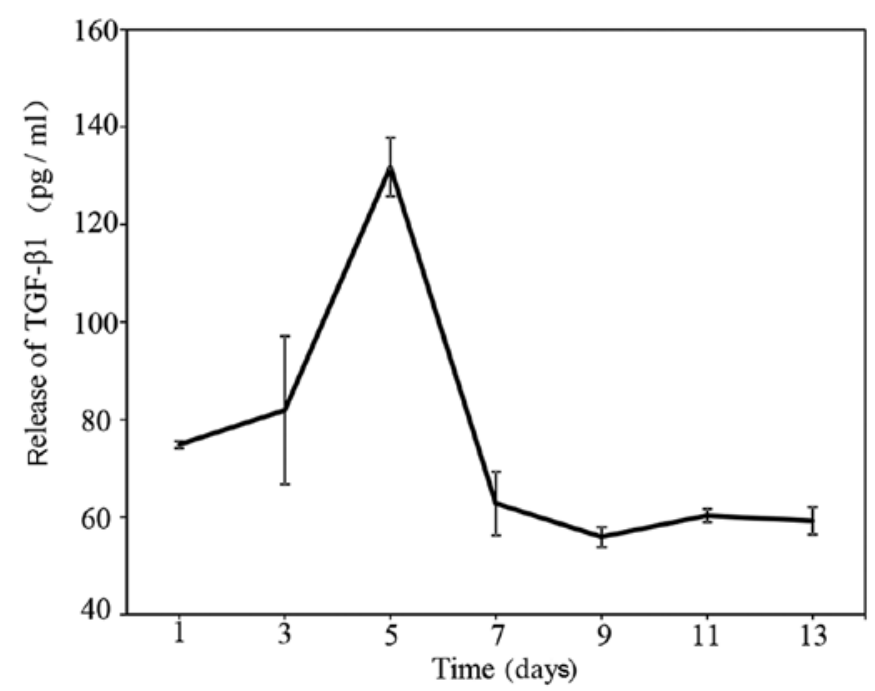

Figure 2. Release of transforming growth factor- $\beta 1$ (TGF- $\beta 1$ ) from concentrated growth factor (CGF). CGF slowly released TGF- $\beta 1$ for up to 13 days. Error bars correspond to the means $\pm \mathrm{SD}$.

straightforward and economical method used to observe cell migration in vitro (20). It imitates, to a certain extent, the migration of cells in vivo. CGF significantly increased the migration rate of the RSC96 SCs in comparison with DMEM. The migration rate of the cells in the CGF group was 4.25-fold greater than that of the cells in the DMEM group $(\mathrm{P}<0.05)$.

$C G F$ increases integrin $\beta 1$ protein expression. Integrin $\beta 1$ is essential for the migration of SCs $(6,19)$. FAK is a cytoplasmic tyrosine kinase that plays critical roles in integrin-mediated signal transductions, and it is phosphorylated following activation (27). Fig. 4 shows the protein expression of integrin $\beta 1$ and p-FAK. There was a statistically significant $(\mathrm{P}<0.05)$ increase in the integrin $\beta 1$ and p-FAK levels following treatment with CGF compared with DMEM. The integrin $\beta 1$ levels increased 1.62-fold on day 1, 1.54-fold on day 2, and 1.14-fold on day 3 . The p-FAK levels were increased 1.46-fold on day 1, 1.80-fold on day 2 and 1.40 -fold on day 3 . These results suggest that integrin $\beta 1$ is involved in the CGF-induced migration of SCs, and that the FAK signaling pathway is activated.

Silencing of integrin $\beta 1$ using siRNA. In order to reveal whether integrin $\beta 1$ plays an essential role in the CGF-induced migration of SCs, integrin $\beta 1$ was silenced by different siRNAs. As shown in Figure 5A, no significant change in the integrin $\beta 1 \mathrm{mRNA}$ level was observed in the siRNA-N group compared with that the normal (untransfected) cells. Transfection with siRNA-1 decreased the integrin $\beta 1$ mRNA level by approximately $50 \%$, transfection with siRNA- 2 decreased the integrin $\beta 1$ mRNA level by $70-80 \%$ and transfection with siRNA-3 reduced the integrin $\beta 1$ mRNA level by $30-40 \%$. Fig. 5B and $C$ show the protein expression of integrin $\beta 1$ following transfection. No significant change was observed in the siRNA-N group. Among the targeted siRNA groups, transfection with siRNA-2 significantly reduced the protein expression of integrin $\beta 1$ by almost 70\%. Thus, siRNA-2 was selected for use in the subsequent experiments.

Transwell migration assay. Transwell migration assays were performed to detect changes in cell migration after integrin $\beta 1$ was downregulated by siRNA-2. Fig. 6 shows that Lipofectamine 2000, which was used as a transfection reagent, did not affect the migration of the SCs. Following the application of siRNA-2, the cell migration rates were decreased significantly by $67 \%$ in the DMEM-treated group, and by $50 \%$ in the CGF-treated group. Moreover, the migration rate of the cells in the CGF treatment group was significantly higher than that of the cells in the DMEM treatment group. This demonstrates that CGF promotes the migration of SCs even after 

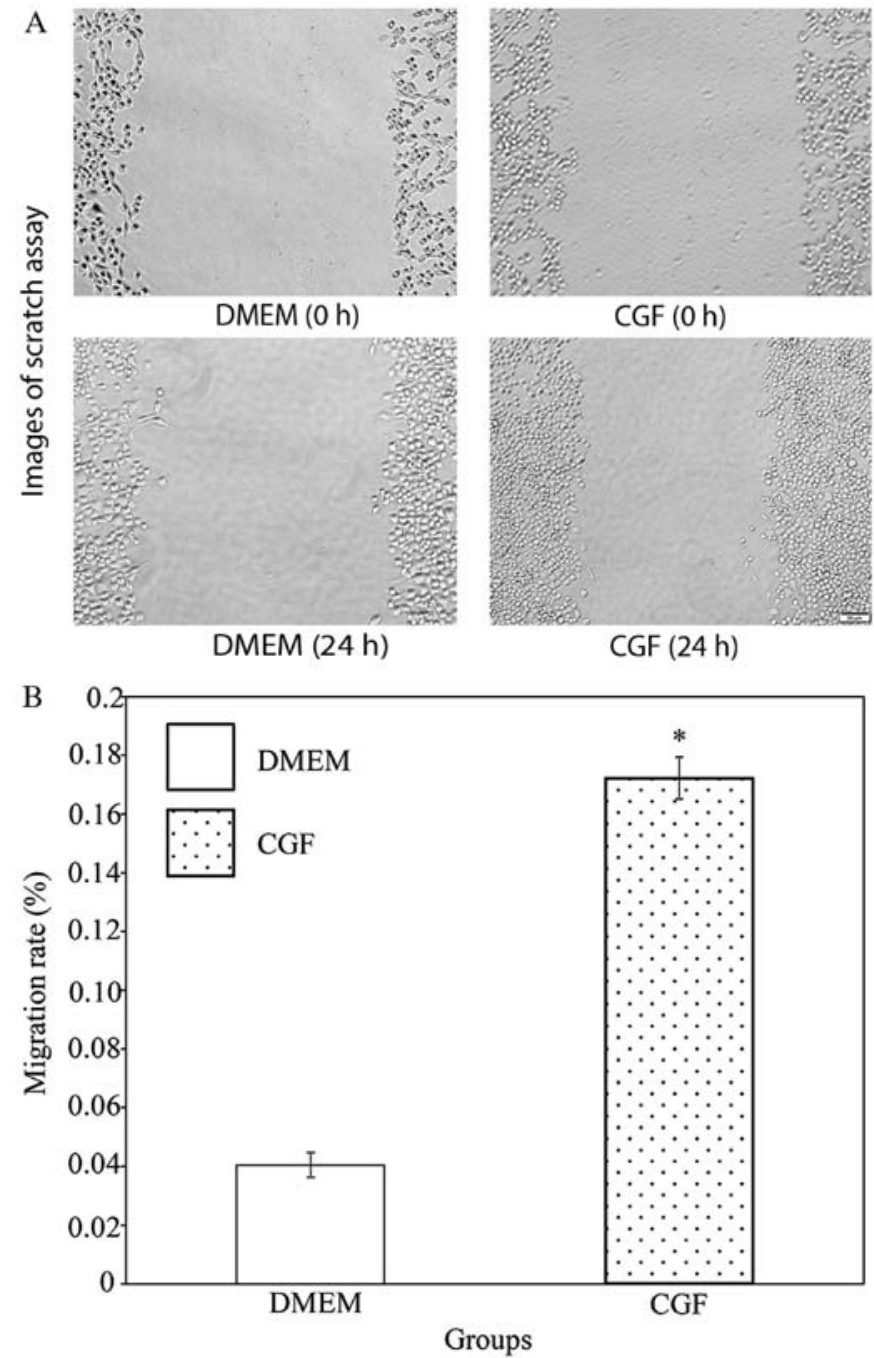

Figure 3. Analysis of the migration of Schwann cells (SCs) treated with DMEM or concentrated growth factor (CGF). (A) Images of scratch wound-healing assay. (B) Migration rate calculated using the images of the scratch wound-healing assay. CGF significantly increased the migration of SCs in comparison with DMEM. The migration rate of the cells in the CGF-treatd group was 4.25-fold higher than that of the cells in the DMEM-treated group. Error bars correspond to the means $\pm \mathrm{SD}$; "P $<0.05$ vs. DMEM-treated group.

integrin $\beta 1$ silencing, indicating that integrin $\beta 1$ plays only a partial role in the CGF-induced migration of SCs, and that other pathways are also involved in this process.

\section{Discussion}

Dental implants are used to reconstruct occlusion. Dental implant surgery itself, however, may damage the nerves. One of the major challenges in nerve regeneration studies is to identify agents capable of promoting the migration of SCs (28-30). CGF is a promising candidate which has shown several advantages. It is prepared from autologous venous blood without the addition of anticoagulant; thus, the clinical use of CGF is safe and does not elicit immune-rejection or an inflammatory response (15). Moreover, the preparation of CGF is rapid, simple, convenient and economical. CGF contains a number of growth factors, including TGF- $\beta 1$, VEGF, IGF, PDGF-AB and IL- $1 \beta$ which all

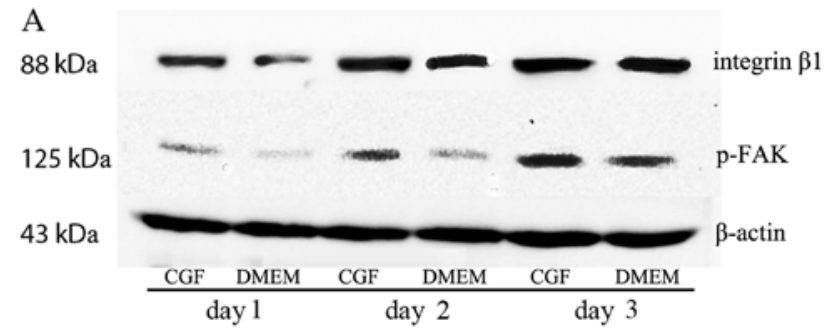

B

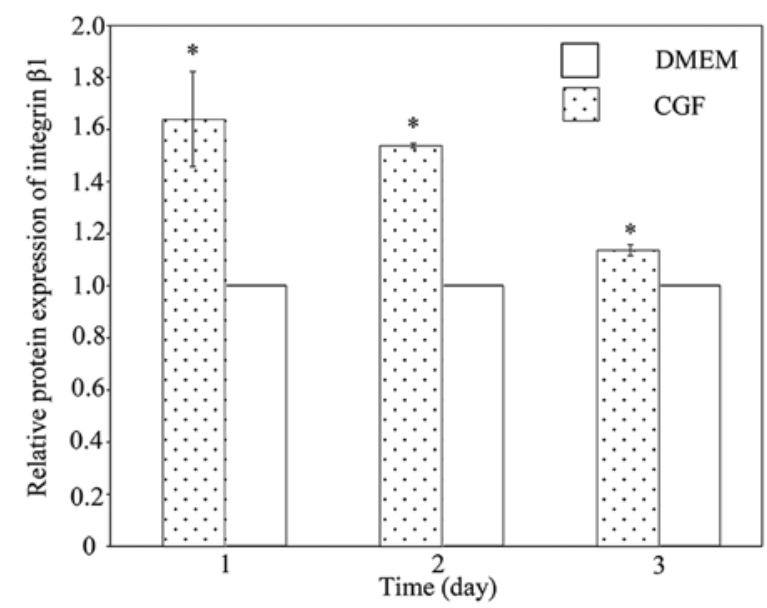

$\mathrm{C}$

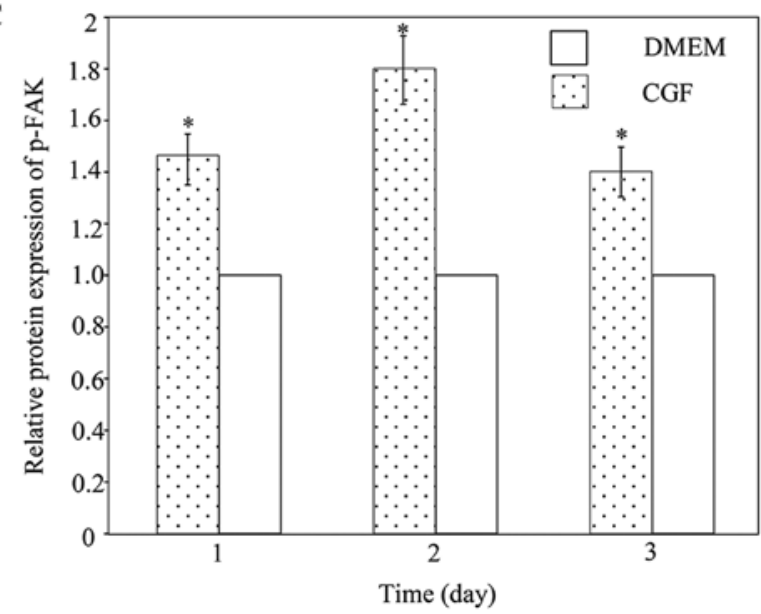

Figure 4. Analysis of integrin $\beta 1$ and phosphorylated (p)-focal adhesion kinase (FAK) protein expression in Schwann cells (SCs). The bands were quantified by densitometry, and the data are expressed as the ratio of target protein to $\beta$-actin. (A and B) Concentrated growth factor (CGF) significantly increased the protein levels of integrin $\beta 1$ by 1.62-, 1.54- and 1.14-fold on days 1,2 and 3 , respectively. (A and C) CGF significantly increased the protein levels of p-FAK by 1.46-, 1.80- and 1.40-fold on days 1, 2 and 3. Error bars correspond to the means $\pm \mathrm{SD} ;{ }^{*} \mathrm{P}<0.05$ vs. DMEM-treated group.

affect the migration of diverse cell types (31-34). To the best of our knowledge, the present study represents the first study on the structural characterization of CGF, the effect of CGF on the migration of SCs and the role of integrin $\beta 1$ and FAK in the CGF-induced migration of SCs.

The structure of the fibrin mesh is known to affect the release of growth factors from platelet concentrates $(10,12)$; thus, the surface morphology of CGF was initially examined under a SEM in this study. The fibrin matrix is composed of three-dimensional polymer networks with interwoven fibers. This type of structure protects against the degradation of the platelets and controls the release of growth factors trapped within $(10,12)$. This is supported by our results, which showed 


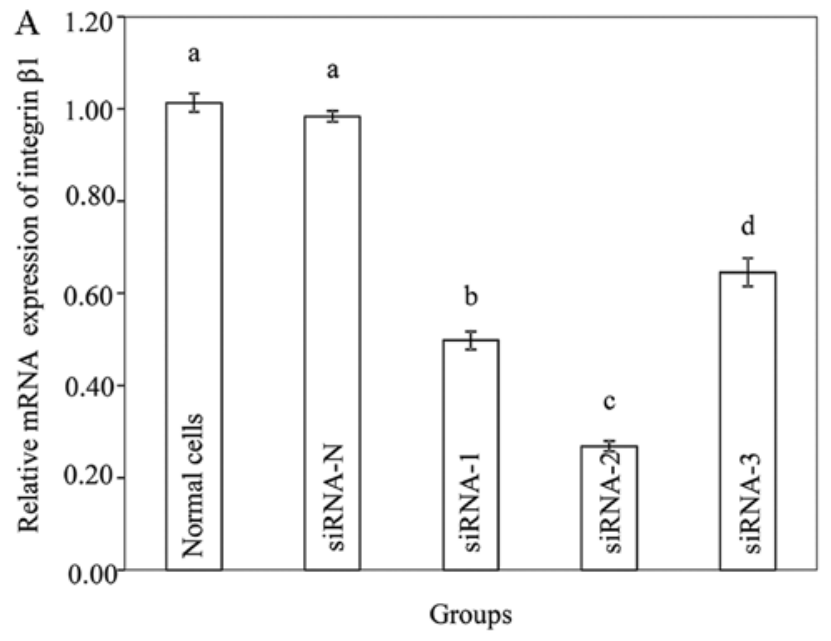

B
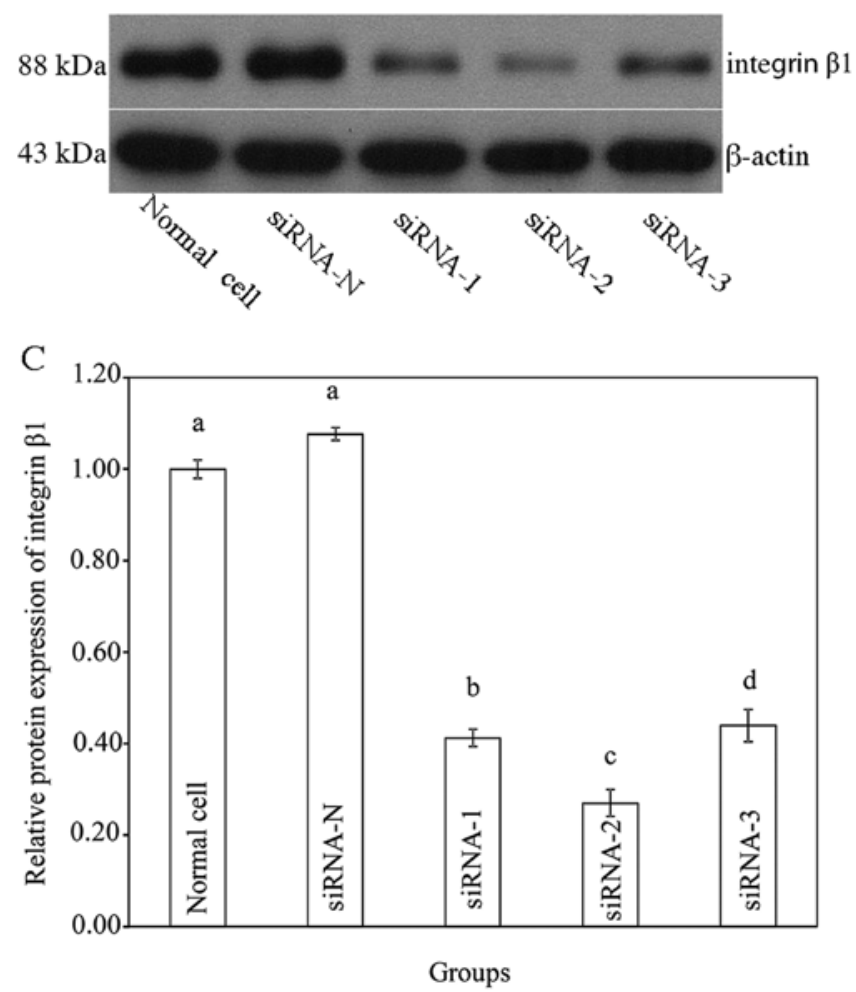

Figure 5. Analysis of of integrin $\beta 1$ expression following transfection with different siRNAs. (A) Analysis of integrin $\beta 1$ mRNA expression using RT-qPCR. siRNA-2 had the most significant inhibitory effect on integrin $\beta 1$ mRNA expression. (B and C) Analysis of integrin $\beta 1$ protein expression using western blot analysis. The bands were quantified by densitometry, and the data are expressed as the ratio of target protein to $\beta$-actin. siRNA-2 had the most significant inhibitory effect on integrin $\beta 1$ protein expression. Error bars correspond to the means $\pm \mathrm{SD}$; Bars with dissimilar letters indicate significant differences from each other $(\mathrm{P}<0.05)$.

that the release of TGF- $\beta 1$ lasted for at least 13 days. Honda et al reported similar results; CGF slowly released cytokines for 9-13 days (24). However, the peak concentration of TGF- $\beta 1$ in the study by Honda et al was much higher than that in our study. This may be due to the following reasons: i) the difference in blood volume used in the experiments. Honda et al used $10 \mathrm{ml}$ blood to prepare CGF, twice the amount that we used, and CGF was soaked in $1 \mathrm{ml}$ of PBS, just one fifth of what we used; ii) the level of growth factors differs between species. Das et al
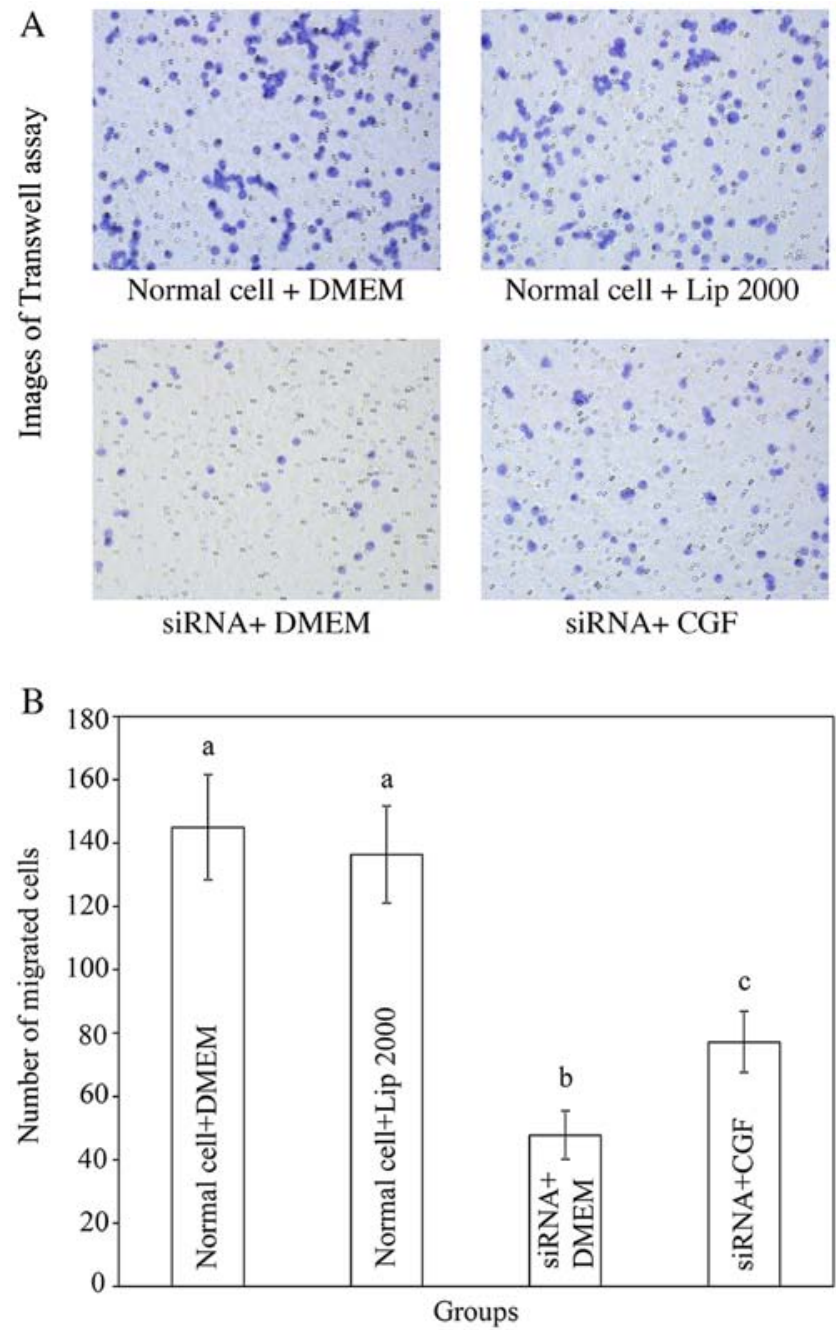

Figure 6. Analysis of the migration of Schwann cells (SCs) following the silencing of integrin $\beta 1$. (A) Images of Transwell analysis. (B) Migrated cells calculated according to the images from the Transwell assay. The transfection reagent [Lipofectamine (Lip) 2000] did not effect the migration of SCs. Although siRNA-2 significantly reduced the migration of SCs, the number of migrated cells in the concentrated growth factor (CGF)-treated group remained significantly higher than those in DMEM-treated group. Error bars correspond to the means $\pm \mathrm{SD}$; Bars with dissimilar letters indicate significant differences from each other $(\mathrm{P}<0.05)$.

reported that the TGF- $\beta 1$ level in rat serum was $15.8 \pm 3.32 \mathrm{pg} /$ $\mathrm{ml}$ (35), whereas Kropf et al reported higher levels of TGF- $\beta 1$ in human serum ranging from 24.2 to $257 \mathrm{ng} / \mathrm{ml}$ (36).

The adequate migration of SCs is crucial for the regenerative process following peripheral nerve injury. RSC96 is a spontaneously transformed rat SC line derived from the long-term culture of primary rat SCs. Due to difficulties in the isolation and culture of primary SCs, the RSC96 cell line has been employed successfully in previous studies $(28,30)$. In the present study, the RSC96 cell line was cultured and treated with CGF. CGF extract was used as conditioned medium in our experiments.

Another noteworthy finding of this study was the significant effect of CGF on the increased migration of SCs, which has not been reported previously, to the best of our knowledge. This CGF-induced increase in the migration of SCs may possibly be mediated by the growth factors released by CGF, as those growth factors identified in CGF independently promote the 
migration of a wide variety of cell types. For example, previous research has found that TGF facilitates the migration of cancer cells (31), VEGF stimulates the migration of endothelial cells (32) and PDGF enhances the migration of retinal pigment epithelial cells (33). IGF-I has also been shown to stimulate the directional migration of numerous peripheral cells (34). Apart from these growth factors, Li et al suggested that chemokines released by leukocytes trapped in CGF, as well as the soluble fibrin components may also play roles in cell migration as chemoattractant (37).

In order to reveal the underlying mechanism responsible for the effects of CGF, an experiment to determine integrin $\beta 1$ expression levels was conducted as it plays a role in the migration of SCs $(6,19)$. In this study, the expression of integrin $\beta 1$ and its downstream molecule FAK were increased in the SCs following CGF treatment, indicating that the CGF-induced cell migration was associated with the integrin $\beta 1$ pathway. The possible mechanisms involved may be the cross-talk between growth factor receptor and integrin. There are several types of growth factor receptors on SCs, including the IGF receptor (38), the PDGF receptor (38) and the fetal liver kinase-1 (flk-1) receptor (39). It has been reported that there is cross-activation between growth factor receptor and integrin (40); therefore, the activation of growth factor receptor may induce integrin activation. Thus, the growth factors in CGF may bind to the corresponding growth factor receptors and then activate integrin $\beta 1$ in order to modulate the migration of SCs.

In order to investigate whether integrin $\beta 1$ plays an essential role in the CGF-induced migration of SCs, integrin $\beta 1$ was silenced by siRNA, which interferes in the expression of specific RNA. Following integrin $\beta 1$ gene silencing, the migratory ability of the SCs in the CGF-treated group was still significantly higher than that of the SCs in the DMEM-treated group. These results suggested that integrin $\beta 1$ did not play an essential role in the CGF-induced migration of SCs. There may be some other integrins involved in this process, since there are several types of integrin expressed on SCs, such as integrin $\alpha 5$ (41), integrin $\alpha 6$, and integrin $\alpha 7$ (42). Similar results obtained by other researchers, have demonstrated that the integrin $\alpha 5$ antibody did not affect the growth factor-induced migration of smooth muscle cells (43).

The capacity of the sustained release of growth factors, the promotion of SC migration, autologous nature, easy preparation and safety, without the risk associated with allogeneic products renders CGF a promising biomaterial for its clinical application for nerve regeneration. In order to elucidate the exact mechanisms involved in the promoting effects of CGF on the cell migration process, the assessment of the effects of other integrins on the CGF-induced migration of SCs must be performed in future studies. In addition, it is important to investigate the in vivo effects of CGF on nerve regeneration. It is also necessary to perform further neural electrophysiological studies using animal models prior to examining the clinical application of CGF in peripheral nerve regeneration following injury.

\section{Acknowledgements}

Financial support from the Jilin Province Science Foundation (grant no. 2014Z044), the Funding for Top Talents among PhD students in Jilin University, the National Natural Science Foundation of China (Youth Scholar Program, grant no. 81400487), the Jilin Province Science Foundation for Youths (grant no. 20150520043JH), and the Excellent Youth Scholars of Bethune Medical Department in Jilin University (grant no. 2013208064), is gratefully acknowledged.

\section{References}

1. Juodzbalys G, Wang HL, Sabalys G, Sidlauskas A and Galindo-Moreno P: Inferior alveolar nerve injury associated with implant surgery. Clin Oral Implants Res 24: 183-190, 2013.

2. Kim YT, Pang KM, Jung HJ, Kim SM, Kim MJ and Lee JH: Clinical outcome of conservative treatment of injured inferior alveolar nerve during dental implant placement. J Korean Assoc Oral Maxillofac Surg 39: 127-133, 2013.

3. Gaudet AD, Popovich PG and Ramer MS: Wallerian degeneration: gaining perspective on inflammatory events after peripheral nerve injury. J Neuroinflammation 8: 110, 2011.

4. Torigoe K, Tanaka HF, Takahashi A, Awaya A and Hashimoto K: Basic behavior of migratory Schwann cells in peripheral nerve regeneration. Exp Neurol 137: 301-308, 1996.

5. Anton ES, Weskamp G, Reichardt LF and Matthew WD: Nerve growth factor and its low-affinity receptor promote Schwann cell migration. Proc Natl Acad Sci USA 91: 2795-2799, 1994.

6. Inoue G, Gaultier A, Li X, Mantuano E, Richardson G, Takahashi K and Campana WM: Erythropoietin promotes Schwann cell migration and assembly of the provisional extracellular matrix by recruiting betal integrin to the cell surface. Glia 58: 399-409, 2010.

7. Perrin LA, June JE, Rosebury W, Robertson A, Kovesdi I, Bruder JT, Kessler PD, Keiser JA and Gordon D: Increased revascularization efficacy after administration of an adenovirus encoding VEGF(121). Gene Ther 11: 512-521, 2004.

8. Whalen GF, Shing Y and Folkman J: The fate of intravenously administered bFGF and the effect of heparin. Growth Factors 1: 157-164, 1989.

9. Edelman ER, Mathiowitz E, Langer R and Klagsbrun M: Controlled and modulated release of basic fibroblast growth factor. Biomaterials 12: 619-626, 1991.

10. Schär MO, Diaz-Romero J, Kohl S, Zumstein MA and Nesic D: Platelet-rich concentrates differentially release growth factors and induce cell migration in vitro. Clin Orthop Relat Res 473: 1635-1643, 2015.

11. Dohan Ehrenfest DM, de Peppo GM, Doglioli P and Sammartino G: Slow release of growth factors and thrombospondin-1 in Choukroun's platelet-rich fibrin (PRF): a gold standard to achieve for all surgical platelet concentrates technologies. Growth Factors 27: 63-69, 2009.

12. Dohan Ehrenfest DM,Bielecki T,JimboR,Barbé G,DelCorso M, Inchingolo F and Sammartino G: Do the fibrin architecture and leukocyte content influence the growth factor release of platelet concentrates? An evidence-based answer comparing a pure platelet-rich plasma (P-PRP) gel and a leukocyte- and plateletrich fibrin (L-PRF). Curr Pharm Biotechnol 13: 1145-1152, 2012.

13. Kawase T: Platelet-rich plasma and its derivatives as promising bioactive materials for regenerative medicine: basic principles and concepts underlying recent advances. Odontology 103: 126-135, 2015. doi: 10.1007/s10266-015-0209-2.

14. Rodella LF, Favero G, Boninsegna R, Buffoli B, Labanca M, Scarì G, Sacco L, Batani T and Rezzani R: Growth factors, CD34 positive cells, and fibrin network analysis in concentrated growth factors fraction. Microsc Res Tech 74: 772-777, 2011.

15. Sohn DS, Heo JU, Kwak DH, Kim DE, Kim JM, Moon JW, Lee JH and Park IS: Bone regeneration in the maxillary sinus using an autologous fibrin-rich block with concentrated growth factors alone. Implant Dent 20: 389-395, 2011.

16. Yu B and Wang Z: Effect of concentrated growth factors on beagle periodontal ligament stem cells in vitro. Mol Med Rep 9: 235-242, 2014.

17. Hynes RO: Integrins: versatility, modulation, and signaling in cell adhesion. Cell 69: 11-25, 1992.

18. Taskinen HS, Heino J and Röyttä M: The dynamics of beta 1 integrin expression during peripheral nerve regeneration. Acta Neuropathol 89: 144-151, 1995.

19. Byzova TV, Goldman CK, Pampori N, Thomas KA, Bett A, Shattil SJ and Plow EF: A mechanism for modulation of cellular responses to VEGF: activation of the integrins. Mol Cell 6: 851-860, 2000. 
20. Liang CC, Park AY and Guan JL: In vitro scratch assay: a convenient and inexpensive method for analysis of cell migration in vitro. Nat Protoc 2: 329-333, 2007.

21. Felice F, Zambito Y, Belardinelli E, Fabiano A, Santoni T and Di Stefano R: Effect of different chitosan derivatives on in vitro scratch wound assay: a comparative study. Int J Biol Macromol 76: 236-241, 2015.

22. Yu JY, DeRuiter SL and Turner DL: RNA interference by expression of short-interfering RNAs and hairpin RNAs in mammalian cells. Proc Natl Acad Sci USA 99: 6047-6052, 2002.

23. Li Q, Reed DA, Min L, Gopinathan G, Li S, Dangaria SJ, Li L, Geng Y, Galang MT, Gajendrareddy P, et al: Lyophilized platelet-rich fibrin (PRF) promotes craniofacial bone regeneration through Runx2. Int J Mol Sci 15: 8509-8525, 2014.

24. Honda H, Tamai N, Naka N, Yoshikawa H and Myoui A: Bone tissue engineering with bone marrow-derived stromal cells integrated with concentrated growth factor in Rattus norvegicus calvaria defect model. J Artif Organs 16: 305-315, 2013.

25. Li M, Zhang P, Li H, Zhu Y, Cui S and Yao D: TGF- $\beta 1$ is critical for Wallerian degeneration after rat sciatic nerve injury. Neuroscience 284: 759-767, 2015.

26. Luo H, Zhang Y, Zhang Z and Jin Y: The protection of MSCs from apoptosis in nerve regeneration by TGF $\beta 1$ through reducing inflammation and promoting VEGF-dependent angiogenesis. Biomaterials 33: 4277-4287, 2012.

27. Zhao $X$ and Guan JL: Focal adhesion kinase and its signaling pathways in cell migration and angiogenesis. Adv Drug Deliv Rev 63: 610-615, 2011.

28. Chang HM, Shyu MK, Tseng GF, Liu CH, Chang HS, Lan CT, Hsu WM and Liao WC: Neuregulin facilitates nerve regeneration by speeding Schwann cell migration via ErbB2/3-dependent FAK pathway. PLoS One 8: e53444, 2013.

29. Perlin JR, Lush ME, Stephens WZ, Piotrowski T and Talbot WS Neuronal Neuregulin 1 type III directs Schwann cell migration. Development 138: 4639-4648, 2011.

30. Chang YM, Shih YT, Chen YS, Liu CL, Fang WK, Tsai CH, Kuo WW, Lai TY and Huang CY: Schwann cell migration induced by earthworm extract via activation of PAs and MMP2/9 mediated through ERK1/2 and p38. Evid Based Complement Alternat Med 2011: 395458, 2011.

31. Takai E, Tsukimoto M, Harada H, Sawada K, Moriyama Y and Kojima S: Autocrine regulation of TGF- $\beta 1$-induced cell migration by exocytosis of ATP and activation of $\mathrm{P} 2$ receptors in human lung cancer cells. J Cell Sci 125: 5051-5060, 2012

32. Morales-Ruiz M, Fulton D, Sowa G, Languino LR, Fujio Y, Walsh K and Sessa WC: Vascular endothelial growth factor-stimulated actin reorganization and migration of endothelial cells is regulated via the serine/threonine kinase Akt. Circ Res 86 : $892-896,2000$
33. Chan CM, Chang HH, Wang VC, Huang CL and Hung CF: Inhibitory effects of resveratrol on PDGF-BB-induced retinal pigment epithelial cell migration via PDGFR $\beta$, PI3K/Akt and MAPK pathways. PLoS One 8: e56819, 2013.

34. Maucksch C, McGregor AL, Yang M, Gordon RJ, Yang M and Connor B: IGF-I redirects doublecortin-positive cell migration in the normal adult rat brain. Neuroscience 241: 106-115, 2013.

35. Das SK, Dhanya L, Varadhan S, Mukherjee S and Vasudevan DM: Effects of chronic ethanol consumption in blood: a time dependent study on rat. Indian J Clin Biochem 24: 301-306, 2009.

36. Kropf J, Schurek JO, Wollner A and Gressner AM: Immunological measurement of transforming growth factor-beta 1 (TGF-beta1) in blood; assay development and comparison. Clin Chem 43. 1965-1974, 1997.

37. Li Q, Pan S, Dangaria SJ, Gopinathan G, Kolokythas A, Chu S, Geng Y, Zhou Y and Luan X: Platelet-rich fibrin promotes periodontal regeneration and enhances alveolar bone augmentation. Biomed Res Int 2013: 638043, 2013

38. Ammoun S, Schmid MC, Ristic N, Zhou L, Hilton D, Ercolano E, Carroll $\mathrm{C}$ and Hanemann CO: The role of insulin-like growth factors signaling in merlin-deficient human schwannomas. Glia 60: 1721-1733, 2012.

39. Sondell M, Lundborg G and Kanje M: Vascular endothelial growth factor has neurotrophic activity and stimulates axonal outgrowth, enhancing cell survival and Schwann cell proliferation in the peripheral nervous system. J Neurosci 19: 5731-5740, 1999.

40. Mahabeleshwar GH, Feng W, Reddy K, Plow EF and Byzova TV: Mechanisms of integrin-vascular endothelial growth factor receptor cross-activation in angiogenesis. Circ Res 101: 570-580, 2007.

41. Wakatsuki S, Araki T and Sehara-Fujisawa A: Neuregulin-1/glial growth factor stimulates Schwann cell migration by inducing $\alpha 5 \beta 1$ integrin-ErbB2-focal adhesion kinase complex formation. Genes Cells 19: 66-77, 2014.

42. Pellegatta M,De Arcangelis A, D'Urso A, Nodari A,Zambroni D, Ghidinelli M, Matafora V, Williamson C, Georges-Labouesse E, Kreidberg J, et al: $\alpha 6 \beta 1$ and $\alpha 7 \beta 1$ integrins are required in Schwann cells to sort axons. J Neurosci 33: 17995-18007, 2013.

43. Itoh H, Nelson PR, Mureebe L, Horowitz A and Kent KC: The role of integrins in saphenous vein vascular smooth muscle cell migration. J Vasc Surg 25: 1061-1069, 1997. 